\title{
Furcation Involvement Classifications: A Critical Appraisal and Proposal for a New System
}

\author{
Rejina Shrestha ${ }^{1 \odot}$, Amar Bhochhibhoya ${ }^{2 \odot}$
}

\begin{abstract}
Aim and objective: This article aims to emphasize the use of a new classification system with a review of the classification systems devised in the past along with their limitations.

Background: There is a lack of universal acceptance of single classification system for furcation involvement due to certain limitations and drawbacks. So, there is a need for a new approach to address the lacuna in the present classification systems. A thorough literature search was done in Medline/PubMed and Google Scholar to incorporate all the classification systems which have been proposed previously.

Review results: Different classifications have been proposed over different eras, the classification given by Glickman being the most common one. The proposed system is based on the site-specific clinical presentation of the furcation defects and takes into consideration the horizontal and vertical components of furcation as well as its exposure.

Conclusion: The present classification has been underscored which is entirely clinical in nature, avoiding the need for anaesthesia, radiographs and open surgeries. This simple and convenient system will assist the clinical practitioners to record the furcation invasion and aid to visualize the clinical picture of the involved tooth.

Clinical significance: This simple and convenient system will assist the clinical practitioners to record the furcation invasion and aid to visualize the clinical picture of the involved tooth.

Keywords: Classification, Furcation invasion, Proposal.

CODS Journal of Dentistry (2021): 10.5005/jp-journals-10063-0082
\end{abstract}

\section{BACKGROUND}

"Periodontitis is a chronic multifactorial inflammatory disease associated with dysbiotic plaque biofilms and characterized by progressive destruction of the tooth-supporting apparatus." ${ }^{11}$ Treatment of periodontitis comprises a wide array of nonsurgical and surgical therapies. Regardless of the contemporary treatment options, therapy becomes additionally complex when the multirooted tooth is affected resulting in furcation exposure. ${ }^{2}$

A furcation invasion is defined as the extension of periodontitis or pulpitis into a trifurcation area. ${ }^{3}$ The pathogenesis of furcation invasion commences with the widening of the periodontal space and inflammatory exudation, eventually leading to the epithelial proliferation into the furcation area from the adjacent periodontal pockets. ${ }^{4}$ Furcation creates a potential niche for bacterial plaque, toxins and calculus accumulation. The anatomy and morphology of the furcation coupled with limited accessibility for instrumentation further increases the possibility of periodontitis. The complexity is heightened by the severe attachment loss resulting in a poor crown-to-root ratio and/or increased tooth mobility. ${ }^{5}$ In cases of furcation involved tooth, the risk of tooth loss is increased by 2.21-2.54 times in the maintenance phase than in teeth without furcation involvement. ${ }^{6,7}$

Furcation involvement is more common in maxillary molars than in mandibular molars, ${ }^{8}$ the prevalence being $25-52 \%$ in the maxillary molars and $16-35 \%$ in the mandibular molars. ${ }^{9-13}$ The first molars are more frequently involved than the second molars. ${ }^{14,15}$ According to the site, the distal of the maxillary 1st molar (53\%) are invaded more commonly with the mesial of the maxillary $2 \mathrm{nd}$ molar being invaded the least (20\%).
${ }^{1}$ Periodontology and Oral Implantology Section, Dental Department, National Academy of Medical Sciences, Bir Hospital, Mahaboudha, Kathmandu, Nepal

${ }^{2}$ Department of Prosthodontics, TU Dental Teaching Hospital, Institute of Medicine, Maharajgunj, Kathmandu, Nepal

Corresponding Author: Amar Bhochhibhoya, Department of Prosthodontics, TU Dental Teaching Hospital, Institute of Medicine, Maharajgunj, Kathmandu, Nepal, Phone: +977 9804320719, e-mail: amarbhochhibhoya@gmail.com

How to cite this article: Shrestha R, Bhochhibhoya A. Furcation Involvement Classifications: A Critical Appraisal and Proposal for a New System. CODS J Dent 2021;13(1):11-17.

Source of support: Nil

Conflict of interest: None

Furcation involvement is a local factor that influences the prognosis of the associated tooth. It is rendered to be of utmost importance to determine the prognosis of the tooth and for the selection of the therapy. ${ }^{16}$ This, in turn, aids to claim insurance, to depict time and money invested in the tooth and to play a decisive role for the retention of the concerned tooth in cases of complete rehabilitation. ${ }^{17-19}$ The diagnosis of furcation invasion is made by clinical assessment, probing, transgingival probing, radiographic assessment and open flap procedure. Generally, Glickman's Class I furcation lesions may be simply treated by scaling and root planing ${ }^{20}$ or furcationplasty, Class II by regenerative therapy, ${ }^{21-23}$ Class III and IV by extraction or resective therapy such as hemisection, root resection or tunnel preparation. ${ }^{20,24-26}$

(0) The Author(s). 2021 Open Access This article is distributed under the terms of the Creative Commons Attribution 4.0 International License (https://creativecommons. org/licenses/by-nc/4.0/), which permits unrestricted use, distribution, and non-commercial reproduction in any medium, provided you give appropriate credit to the original author(s) and the source, provide a link to the Creative Commons license, and indicate if changes were made. The Creative Commons Public Domain Dedication waiver (http://creativecommons.org/publicdomain/zero/1.0/) applies to the data made available in this article, unless otherwise stated. 


\section{Review Results}

A thorough literature search was done in Medline/PubMed and Google Scholar to incorporate all the classification systems which have been proposed previously. Many classifications have been described over the years which reveal the extensive researches being done in furcation. Among these classifications, the most commonly used is the Glickman's classification. Different classifications have been summarised in Table 1:

Besides these, the furcation involvement chart proposed by Muller and Eger in $1999^{18}$ shows substantial success in depicting the nature and extent of the furcation involvement.

The classifications proposed previously have added insight to the knowledge of furcation, but are not complete in itself. The classifications given by Glickman, ${ }^{27}$ Goldman, ${ }^{28}$ Staffileno, ${ }^{29}$ Easley and Drennan, ${ }^{30}$ Goldman and Cohen, ${ }^{31}$ Basaraba, ${ }^{32}$ Grant et al. ${ }^{33}$ Svardstrom and Wennstrom, ${ }^{8}$ Nevins and Cappetta, ${ }^{34} \mathrm{GPT}^{3}$ are narrative in nature. Ramfjord and Ash, ${ }^{35}$ Hamp et al., ${ }^{16}$ Rateitschack, ${ }^{36}$ Carnevale, ${ }^{37}$ and Walter et al. ${ }^{38}$ have considered only the horizontal involvement whereas Eskow and Kapin, ${ }^{39}$ Tarnow, ${ }^{40}$ Tal and Lemmer ${ }^{15}$ and Tonetti et al. ${ }^{41}$ have considered only the vertical involvement. Both horizontal and vertical components have been included in the classifications given by Fedi, ${ }^{42}$ Richhetti, ${ }^{43} \mathrm{Hou}$ et al., ${ }^{44}$ Fugazzotto ${ }^{45}$ and Rosenburg. ${ }^{46}$ Considerations of tooth diameter, ${ }^{39,40}$ the height of the root trunk, ${ }^{44}$ the number of remaining bony walls, ${ }^{47}$ the exposure of the furcation ${ }^{48}$ have been advocated.

Some of the classifications do not clearly state the categorization of the furcations. They have classified furcation invasion as less than a certain figure, for example, less than two-third or more than two-third, but do not make an attempt to classify the furcation which is equal to two-third. ${ }^{16,35,37,39,46}$ Classifications have also been done on the basis of radiographic images. ${ }^{38,41}$ In such cases overlapping of the structures in the maxillary molars creates difficulty in the diagnosis.

\section{Proposed New Classification (Shrestha's Furcation Index)}

This system advocates clinical assessment and classification of furcation defects without the need of anaesthesia, radiographs and surgery. Clinical probing provides fairly accurate dimensions of the furcation involvement and has the advantages of being simple, practical and least expensive among all methods. ${ }^{19}$

Although open flap surgeries provide the best picture of the furcation, they are not justified for the measurement of furcation depth. Open flap surgeries cause unnecessary discomfort owing to the reentry surgery, which also has possible traumatic effects. ${ }^{49}$ Vertical and horizontal components have been found to be 0.9-1.1 mm deeper during open flap measurements and probing bone levels. ${ }^{49}$ This may be due to inter-operator variability during measurement or a more ambitious curettage with unintentional removal of bone effects. ${ }^{49}$

The proposed furcation index is greatly influenced by the Smith's index of recession. ${ }^{50}$ This index tries to overcome limitations of previous classification systems and gives a clear picture of the furcation involvement and ensures that important factors such as the site involved, the horizontal component, the vertical component and the furcation exposure, have been taken into consideration.

Similar to the recession index, the proposed index consists of a letter, followed by two digits separated by a dash and ended with an asterisk, when indicated. The first letter of the proposed classification denotes the site of the furcation involvement. This makes examining of the furcation from all possible sides obligatory. Most classifications do not include this element, which fails to give the complete picture of the clinical presentation. The letters used are $\mathrm{M}$ for mesial, B for buccal, D for distal, L for lingual. This specifies the particular site of the furcation involvement and the letters can be easily used for any tooth, including premolars, maxillary molars with two roots or mandibular molars with three roots.

The first digit denotes the horizontal involvement of the furcation (Fig. 1) and the second denotes the vertical component (Fig. 2), the horizontal component always precedes the vertical component. This sequence emphasizes the fact that the actual complexity of the furcation is greatly influenced by the horizontal component rather than the vertical component.

The measurements are made according to the procedure defined by Mealey, ${ }^{17}$ with some modifications. For the horizontal component, a calibrated Naber's probe with $3 \mathrm{~mm}$ marking is inserted into the periodontal pocket along the root surface to locate the initial fluting of the furcation and the distance between the CEJ and furcation fluting is measured (a). It is then inserted and curved till obstruction is felt (b). The horizontal component of the furcation is recorded to the nearest millimeter as the difference between $a$ and $b$. It is then classified according to the criteria as mentioned in Table 2.

In cases of through and through lesions, the obstruction is not felt, whereas in exposed furcation, the measurement is made directly from the initial fluting of the furcation. For the confirmation of through and through involvement, use of two probes is encouraged.

For the vertical component, a straight probe with $1 \mathrm{~mm}$ marking is inserted into the periodontal pocket along the root surface to locate the initial fluting of the furcation and the distance between the CEJ and furcation fluting is measured (a). The probe is inserted apically until resistance is felt and the distance from CEJ to the vertical depth is noted (c). The vertical component of the furcation is recorded to the nearest millimeter as the difference between $a$ and c. It is then classified according to the criteria mentioned in Table 3.

The vertical component of the index is followed by an asterisk, which denotes the presence of exposure of the furcation area. In case of non-exposure, the asterisk is omitted. As explained by Tarnow and Fletcher, the consideration of the vertical component is essential as the prognosis of the tooth will definitely be different although being equally probeable in a horizontal plane. ${ }^{40}$ It aids in the determination of the choice of treatment of root separation, resection, regeneration or extraction. ${ }^{41}$

Even if there is no furcation involvement, the index should be noted as M0-0, B0-0, D0-0. This will remind the operator not to miss the different sites of the furcations present in a single tooth. The essence of the index is in the recognition of the furcation involvement.

Example: For a maxillary molar the M1-0, B 1-1*, D 1-1 would be the complete index. This indicates less than $3 \mathrm{~mm}$ of horizontal involvement in the mesial aspect with no vertical involvement, less than $3 \mathrm{~mm}$ of horizontal and vertical component in the buccal and distal aspects with furcation exposure in the buccal aspect.

\section{Discussion}

There is a lack of universal acceptance of single classification system for furcation involvement due to certain limitations and drawbacks. So, there is the need for a new approach to address the lacuna in the present classification systems. The proposed system is based on 
Table 1: Classifications of furcation involvement

\begin{tabular}{|c|c|}
\hline Author & Classification \\
\hline Glickman $^{27}$ & $\begin{array}{l}\text { Grade I: Pocket formation into the furcation, but intact interradicular bone. } \\
\text { Grade II: Loss of interradicular bone and pocket formation but not extending through to the opposite side. } \\
\text { Grade III:Through-and-through lesion. } \\
\text { Grade IV: Through-and-through lesion with gingival recession, leading to a clearly visible furcation area. }\end{array}$ \\
\hline Goldman ${ }^{28}$ & $\begin{array}{l}\text { Grade I: Incipient lesion. } \\
\text { Grade II: Cul-de-sac lesion. } \\
\text { Grade III:Through-and-through lesion. }\end{array}$ \\
\hline Staffileno ${ }^{29}$ & $\begin{array}{l}\text { Class I: Furcations with a soft tissue lesion extending to furcal level but with minor degree of osseous destruction. } \\
\text { Class II: Furcations with a soft tissue lesion and variable degree of osseous destruction but not a through-and- } \\
\text { through communication through the furca. } \\
\text { Class II F: Furcations with osseous destruction from facial aspect only. } \\
\text { Class II L: Furcations with osseous destruction from lingual aspect only. } \\
\text { Class II M: Furcations with osseous destruction from mesial aspect only. } \\
\text { Class II D: Furcations with osseous destruction from distal aspect only. } \\
\text { Class III: Furcations with osseous destruction with through-and-through communication. }\end{array}$ \\
\hline Easley and Drennan ${ }^{30}$ & $\begin{array}{l}\text { Class I: Incipient involvement, but there is no horizontal component to the furca. } \\
\text { Class II Type 1: Horizontal attachment loss into the furcation. } \\
\text { Class II Type 2: Vertical attachment loss into the furcation. } \\
\text { Class III: Through-and-through attachment loss into the furcation. } \\
\text { Type 1: Horizontal attachment loss into the furcation. } \\
\text { Type 2: Vertical attachment loss into the furcation. }\end{array}$ \\
\hline Hamp et al. ${ }^{16}$ & $\begin{array}{l}\text { Degree I: Horizontal attachment loss }<3 \mathrm{~mm} \text {. } \\
\text { Degree II: Horizontal attachment loss }>3 \mathrm{~mm} \text { not encompassing the total width of the furcation area. } \\
\text { Degree III: Horizontal through-and-through destruction of the periodontal tissue in the furcation area. }\end{array}$ \\
\hline Rosenberg ${ }^{46}$ & $\begin{array}{l}\text { HorizontalDegree I: Probing }<4 \mathrm{~mm} \text {. } \\
\text { Degree II: Probing }>4 \mathrm{~mm} \text {. } \\
\text { Degree III: Two or three furcations classified as degree II are found. } \\
\text { VerticalShallow: Slight lateral extension of an interradicular defect, from the center of the trifurcation in a horizontal } \\
\text { direction. } \\
\text { Deep: Internal furcation involvement but not penetrating the adjacent furcation. }\end{array}$ \\
\hline Ramfjord and $\mathrm{Ash}^{35}$ & $\begin{array}{l}\text { Class I: Tissue destruction }<2 \mathrm{~mm}(1 / 3 \text { of tooth width) into the furcation. } \\
\text { Class II:Tissue destruction }>2 \mathrm{~mm}(>1 / 3 \text { of tooth width). } \\
\text { Class III:Through-and-through involvement. }\end{array}$ \\
\hline Goldman and Cohen ${ }^{31}$ & $\begin{array}{l}\text { Degree I: Involves furcation entrance. } \\
\text { Degree II: Involvement extends under the roof of furcation. } \\
\text { Degree III: Through-and-through involvement. }\end{array}$ \\
\hline Ricchetti, 1982 & $\begin{array}{l}\text { Class I: } 1 \mathrm{~mm} \text { of horizontal invasion. } \\
\text { Class la. } 1-2 \mathrm{~mm} \text { of horizontal invasion. } \\
\text { Class II: } 2-4 \mathrm{~mm} \text { of horizontal invasion. } \\
\text { Class Ila. } 4-6 \mathrm{~mm} \text { of horizontal invasion. } \\
\text { Class III: }>6 \mathrm{~mm} \text { of horizontal invasion. }\end{array}$ \\
\hline Tal and Lemmer ${ }^{15}$ & $\begin{array}{l}\text { Furcation involvement index (FII) scores: } \\
\text { Furcal rating 1: Depth of the furcation is } 0 \mathrm{~mm} \text {. } \\
\text { Furcal rating 2: Depth of the furcation is } 1-2 \mathrm{~mm} \text {. } \\
\text { Furcal rating 3: Depth of the furcation is } 3 \mathrm{~mm} \text {. } \\
\text { Furcal rating 4: Depth of the furcation is } 4 \mathrm{~mm} \text { or more. }\end{array}$ \\
\hline Tarnow and Fletcher ${ }^{40}$ & $\begin{array}{l}\text { For each class of horizontal classification (I-III), a subclass based on the vertical bone resorption was added: } \\
\text { Subclass A: } 0-3 \mathrm{~mm} \text {. } \\
\text { Subclass B: } 4-6 \mathrm{~mm} \text {. } \\
\text { Subclass C: }>7 \mathrm{~mm} \text {. }\end{array}$ \\
\hline Rateitschak et al. ${ }^{36}$ & $\begin{array}{l}\text { Degree 0: no furcation involvement } \\
\text { Degree I: Probing Attachment Level-Horizontal } \leq 3 \mathrm{~mm} \\
\text { Degree II: Probing Attachment Level-Horizontal }>3 \mathrm{~mm} \text {, but the defect does not encompass the whole furcation. } \\
\text { Degree III: through and through furcation. }\end{array}$ \\
\hline Eskow and Kapin ${ }^{39}$ & $\begin{array}{l}\text { Furcation involvement is classified as grade I subclasses A, B, and C (vertical involvement): } \\
\text { Subclass A: Vertical destruction }>1 / 3 \text {. } \\
\text { Subclass B: Vertical destruction of } 2 / 3 \text {. } \\
\text { Subclass C: Vertical destruction beyond apical third of interradicular height. }\end{array}$ \\
\hline
\end{tabular}




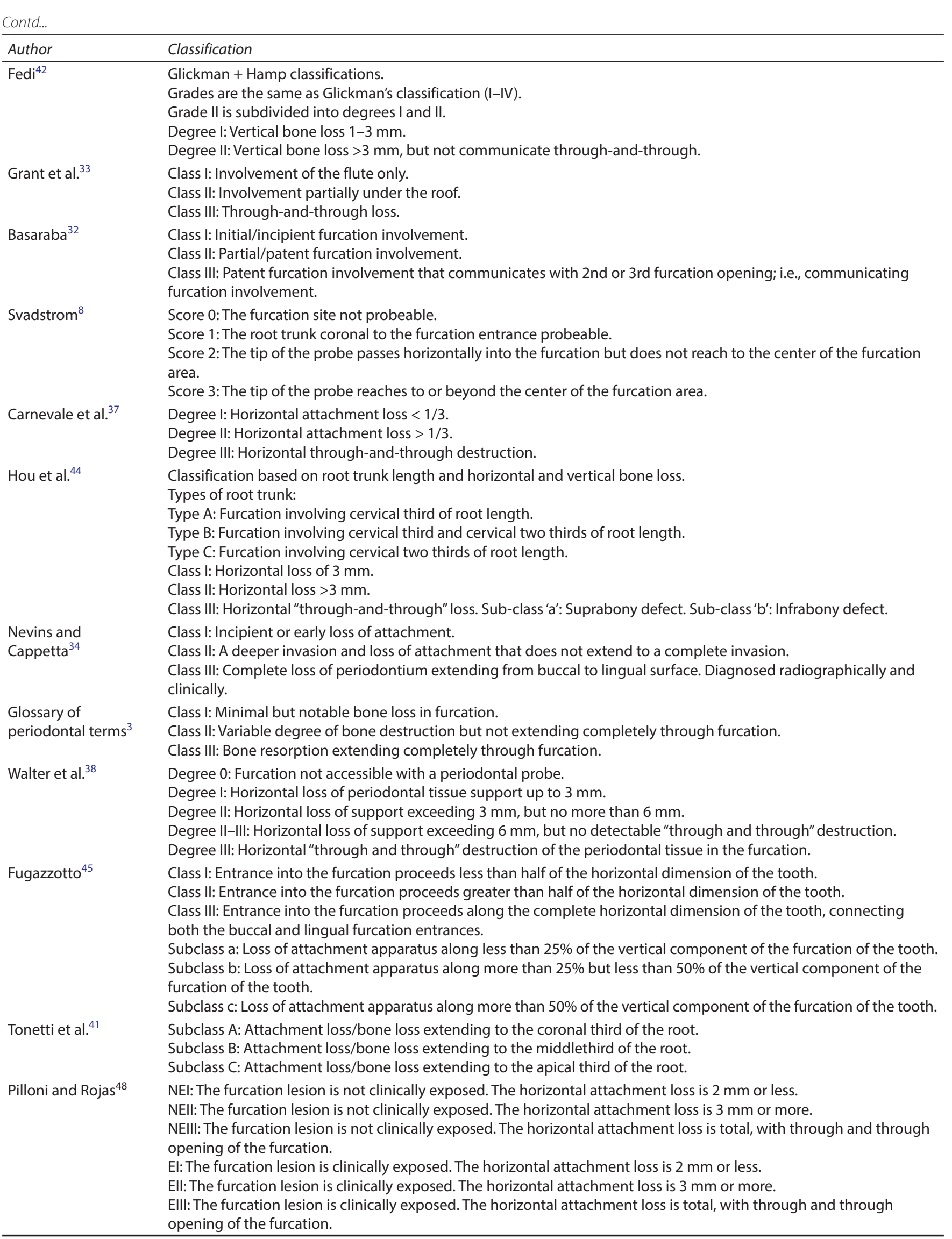


Contd...

\begin{tabular}{ll}
\hline Author & Classification \\
\hline Rasperini et al. $^{2}$ & A1: Horizontal loss of periodontal support $<3 \mathrm{~mm}$ of the width of the tooth with vertical attachment/bone loss \\
extending to the coronal third of the root. & A2: Horizontal loss of periodontal support $<3 \mathrm{~mm}$ of the width of the tooth with vertical attachment/bone loss \\
extending to the middle third of the root. \\
A3: Horizontal loss of periodontal support $<3 \mathrm{~mm}$ of the width of the tooth with vertical attachment/bone loss \\
extending to the apical third of the root. \\
B1: Horizontal loss of periodontal support $\geq 3 \mathrm{~mm}$ of the width of the tooth, but not through and through, with \\
vertical attachment/bone loss extending to the coronal third of the root. \\
B2: Horizontal loss of periodontal support $\geq 3 \mathrm{~mm}$ of the width of the tooth, but not through and through, with \\
vertical attachment/bone loss extending to the middle third of the root. \\
B3: Horizontal loss of periodontal support $\geq 3 \mathrm{~mm}$ of the width of the tooth, but not through and through, with \\
vertical attachment/bone loss extending to the apical third of the root. \\
C1: Horizontal through and through destruction of the periodontal attachment with vertical attachment/bone loss \\
extending to the coronal third of the root. \\
C2: Horizontal through and through destruction of the periodontal attachment with vertical attachment/bone loss \\
extending to the middle third of the root. \\
C3: Horizontal through and through destruction of the periodontal attachment with vertical attachment/bone loss \\
extending to the apical third of the root.
\end{tabular}

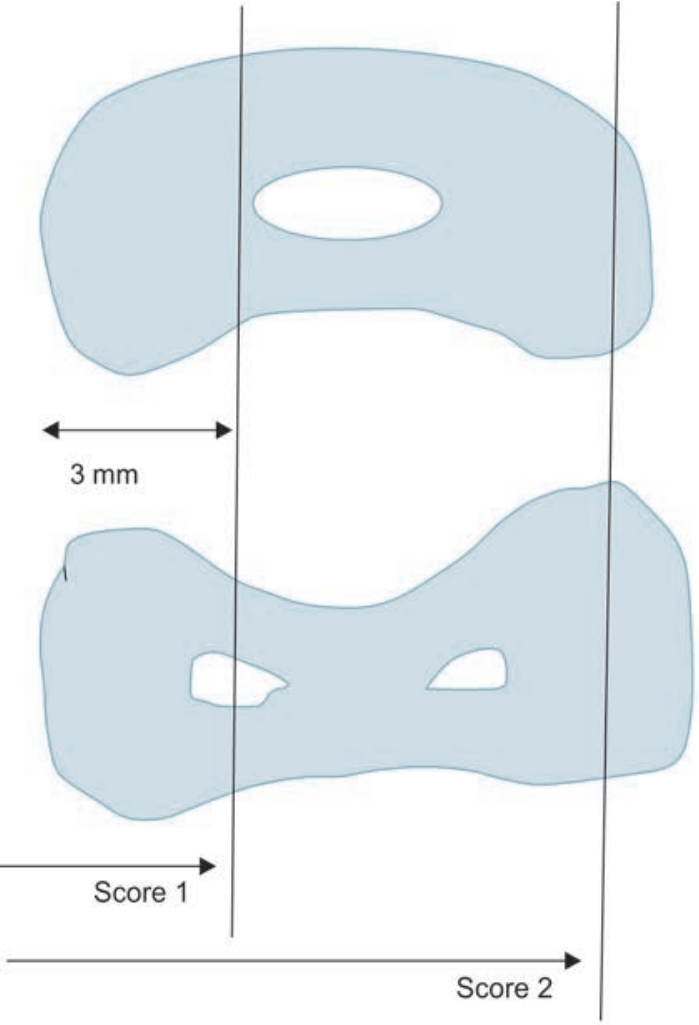

Score 3

Fig. 1: Horizontal component of the furcation. Score 0: no horizontal component. Score 1: Furcation involvement $<3 \mathrm{~mm}$. Score 2: furcation involvement $\geq 3 \mathrm{~mm}$ but not through and through. Score 3: through and through involvement of the furcation

the site-specific clinical presentation of the furcation defects and takes into consideration the horizontal and vertical components of furcation as well as its exposure. This simple and convenient system will assist the clinical practitioners to record the furcation invasion and aid to visualize the clinical picture of the involved tooth.

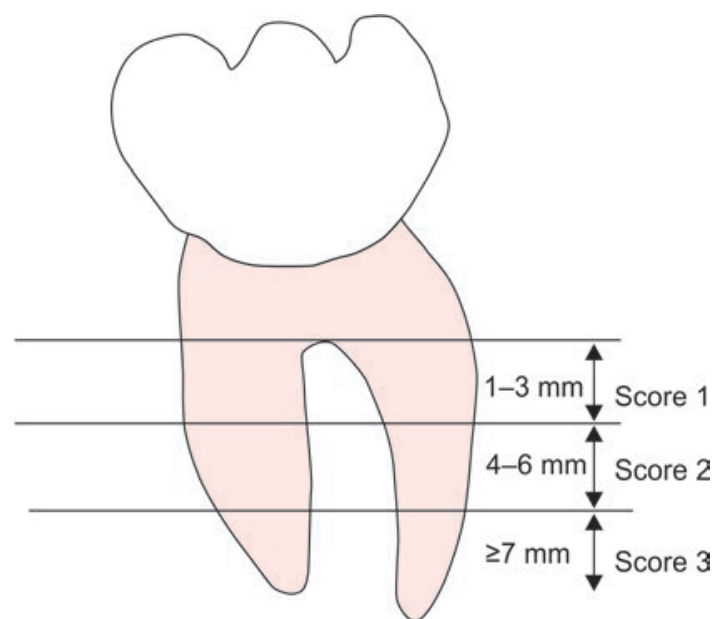

Fig. 2: Vertical component of the furcation. Score 0: no vertical component. Score 1: furcation involvement of 1-3 mm. Score 2: furcation involvement of 4-6 $\mathrm{mm}$. Score 3: furcation involvement of $\geq 7 \mathrm{~mm}$

Table 2: Horizontal component of the furcation

\begin{tabular}{ll}
\hline Score & Criteria \\
\hline 0 & No horizontal component \\
1 & Furcation involvement $<3 \mathrm{~mm}$ \\
2 & Furcation involvement $\geq 3 \mathrm{~mm}$ but not through and through \\
3 & Through and through involvement of the furcation \\
\hline
\end{tabular}

Table 3: Vertical component of the furcation

\begin{tabular}{ll}
\hline Score & Criteria \\
\hline 0 & No vertical component \\
1 & Furcation involvement of $1-3 \mathrm{~mm}$ \\
2 & Furcation involvement of $4-6 \mathrm{~mm}$ \\
3 & Furcation involvement of $\geq 7 \mathrm{~mm}$ \\
\hline
\end{tabular}

It is a site-specific index that would provide qualitative and quantitative information about the furcation and is more objective in its choice of clinical criteria and methodology. Criteria are clear, easy, quickly learned, and is reproducible. It is simple enough to 
be practicable under a wide variety of field conditions and can be adopted for epidemiological studies. The data offers a rapid appreciation of furcation involvement and understanding of prognosis of the tooth and its treatment needs.

The classification will also help to determine the treatment of the furcation lesion. The treatment options are traditionally determined by the horizontal component of the furcation:

For Score 1: Scaling and root planing, Furcationplasty

For Score 2: Furcationplasty, Regeneration, Tunneling, Root separation and resection

For Score 3: Tunneling, Root separation, and resection, Extraction

But the above treatment options should be modified by the involvement of the vertical component of the furcation.

For Score 1: If the vertical component is deep, regeneration should be considered even if there is less horizontal involvement.

For Score 2: The vertical involvement will determine the invasiveness of the treatment. For less vertical involvement, Furcationplasty, Regeneration should be considered. Regeneration should be recommended when the interproximal bone is coronal to the furcation defect. ${ }^{2}$ If there is greater involvement of the vertical component, tunneling and root resection must be considered.

For Score 3: Extraction should only be chosen in case of greater vertical involvement of the furcation.

The acknowledgment of the furcation exposure will help to predict the treatment outcome. It has been inferred that scaling and root planing would be more effective in case of clinically visible furcation. ${ }^{48}$

\section{Limitations}

Overestimation and underestimation are highly probable. Inter and intra-examiner differences exist in measurements of furcation dimensions. The accuracy of probing varies according to the operator's technique, accessibility to furcation and the ability of the patient to open the mouth. ${ }^{4}$ Accessibility is hindered by broad contact areas and the presence of neighboring teeth in proximal furcation.

The horizontal readings are subjected to inaccuracy due to geometry when using a curved probe. A change in horizontal depth of $1 \mathrm{~mm}$ at tip is smaller than at $1 \mathrm{~mm}$ at the edge of the stent. ${ }^{49}$ But, the use of Naber's probe is still recommended because a curved probe facilitates access to furcation area, which is influenced by the position of the gingival margin relative to root trunk length, sloping of fornix aperture, and shape of the roof of furcation dome. ${ }^{49}$

The index does not address factors which are directly involved in furcation involvement such as root concavities, bifurcation ridges, and cervico-enamel projections. Narrow entrances restrict the passage of the probe, which might lead to recording errors. The reference point, the initial fluting of the furcation, may show inaccurate measurement. Other sources of error include interference from calculus, presence of an overhanging restoration or crown contours. ${ }^{51}$

\section{Conclusion}

Different classification systems have evolved in periodontology for furcation invasion. Continuous refinement of these systems with supplementary input provides a broader insight to the practitioner and consequently aids in diagnosis, treatment, prognosis and recording of the disease under consideration. The present classification is the result of an attempt to enhance communication about the detailed information of the furcation invasion to the practitioner. It is easy to use, simple, convenient, and serves as a practical tool both for clinical and research purposes.

\section{Clinical Significance}

The proposed system is based on the site-specific clinical presentation of the furcation defects and takes into consideration the horizontal and vertical components of furcation as well as its exposure.

\section{OrCID}

Rejina Shrestha $\odot$ http://orcid.org/0000-0001-5019-8308

Amar Bhochhibhoya ๑ http://orcid.org/0000-0003-2324-5468

\section{References}

1. Papapanou PN, Sanz M, Buduneli N, et al. Periodontitis: consensus report of workgroup 2 of the 2017 world workshop on the classification of periodontal and peri-implant diseases and conditions. J Periodontol 2018;89:S173-S182. DOI: 10.1111/jcpe.12946

2. Rasperini G, Majzoub J, Limiroli E, et al. Management of furcation-involved molars: recommendation for treatment and regeneration. Int J Periodont Rest 2020;40(4):e137-e146. DOI: $10.11607 /$ prd.4341

3. American Academy of Periodontology. Glossary of periodontal terms, 4th ed. Chicago, LA, USA: American Academy of Periodontology 2001. Available online: https://members.perio.org/libraries/glossary [Accessed 13 July 2020].

4. Darby I, Sanelli M, Shan S, et al. Comparison of clinical and cone beam computed tomography measurements to diagnose furcation involvement. Int J Dent Hyg 2015;13(4):241-245. DOI: 10.1111/idh.12116

5. McGuire MK, Nunn ME. Prognosis versus actual outcome. III. The effectiveness of clinical parameters in accurately predicting tooth survival. J Periodontol 1996;67:666-674. DOI: 10.1902/jop.1996.67.7.666

6. Nibali L, Zavattini A, Nagata K, et al. Tooth loss in molars with and without furcation involvement - a systematic review and meta-analysis. J Clin Periodontol 2016;43:156-166. DOI: 10.1111/jcpe.12497

7. Wang HL, Burgett FG, Shyr Y, et al. The influence of molar furcation involvement and mobility on future clinical periodontal attachment loss. J Periodontol 1994;65(1):25-29. DOI: 10.1902/jop.1994.65.1.25

8. Svärdström G, Wennström JL. Prevalence of furcation involvements in patients referred for periodontal treatment. J Clin Periodontol 1996;23(12):1093-1099. DOI: 10.1111/j.1600-051X.1996. tb01809.x

9. Hörr T, Klein F, Kim TS, et al. Digital radiography for assessment of bony defects. Int Poster J Dent Oral Med 2004;6(1):208.

10. Goldman MJ, Ross IF, Goteiner D. Effect of periodontal therapy onpatients maintained for 15 years or longer. A retrospective study. J Periodontol 1986;57:347-353. DOI: 10.1902/jop.1986.57.6.347

11. Hirschfeld L, Wasserman B. A long term survey of tooth loss in 600 treated periodontal patients. J Periodontol 1978;49:225-237. DOI: 10.1902/jop.1978.49.5.225

12. McFall WT Jr. Tooth loss in 100 treated patients with periodontal disease: a long-term study. J Periodontol 1982;53(9):539-549. DOI: 10.1902/jop.1982.53.9.539

13. Wood WR, Greco GW, McFall WT Jr. Tooth loss in patients with moderate periodontitis after treatment and long-term maintenance care. J Periodontol 1989;60(9):516-520.DOI: 10.1902/jop.1989.60.9.516

14. Larato DC. Furcation involvements: incidence and distribution. J Periodontol 1970;41(9):499-501. DOI: 10.1902/jop.1970.41.9.499

15. Tal H, Lemmer J. Furcal defects in dry mandibles. Part II: severity of furcal defects. J Periodontol 1982;53(6):364-367. DOI: 10.1902/jop.1982.53.6.364 
16. Hamp SE, Nyman S, Lindhe J. Periodontal treatment of multirooted teeth. Results after 5 years. J Clin Periodontol 1975;2:126-135. DOI: 10.1111/j.1600-051X.1975.tb01734.x

17. Mealey BL, Neubauer MF, Butzin CA, et al. Use of furcalbone sounding to improve accuracy of furcation diagnosis. J Periodontol 1994;65:649-657. DOI: 10.1902/jop.1994.65.7.649

18. Muller HP, Eger T. The overall significance of regenerative procedures in the treatment of furcations. Quintessence Int 1997;28:321-328.

19. Karthikeyan BV, Sujatha V, Prabhuji ML. Furcation measurements: realities and limitations. J Int Acad Periodontol 2015;17(4):103-115.

20. Eickholz P, Kim TS. Reproducibility and validity of the assessment of clinical furcation parameters as related to different probes. J Periodontol 1998;69(3):328-336. DOI: 10.1902/jop.1998.69.3.328

21. Becker W, Becker BE, Berg L, et al. New attachment after treatment with root isolation procedures: report for treatedclass III and class II furcations and vertical osseous defects. Int J Periodontics Restorative Dent 1988;8:9-23.

22. Pontoriero R, Lindhe J, Nyman S, et al. Guided tissue regeneration in degree II furcation-involved mandibular molars. J Clin Periodontol 1988;15:247-254.DOI: 10.1111/j.1600-051x.1988.tb01578.x

23. Pontoriero R, Lindhe J. Guided tissue regeneration in the treatment of degree II furcations in maxillary molars. J Clin Periodontol 1995;22(10):756-763. DOI: 10.1111/j.1600-051x.1995. tb00258x

24. Langer B, Stein S, Wagenberg B. An evaluation of root resections. A tenyears study. J Periodontol 1981;52:719-722. DOI: 10.1902/jop.1981.52.12.719

25. Topoll HH, Lange DE. Die Tunnelierung mehrwurzliger Zähne. Ergebnisse 8 Jahre post operationem. Dtsch Zahnärztl Z 1987;42:445-449.

26. Hellden LB, Elliot A, Steffensen B, et al. The prognosis of tunnel preparations in treatment of class III furcations: a follow-up study. J Periodontol 1989;60(4):182-187. DOI: 10.1902/jop.1989.60.4.182

27. Glickman I. Clinical periodontology. 2nd ed. Philadelphia: W. B. Saunders; 1958.694-696.

28. Goldman H. Therapy of the incipient bifurcation involvement. J Periodontol 1958;29:112-116. DOI: 10.1902/jop.1958.29.2.112

29. Staffileno HJ. Surgical management of the furca invasion. Dent Clin N Am 1969;13(1):103-119.

30. Easley JR, Drennan GA. Morphological classification of the furca. J Can Dent Assoc 1969;35:104-107.

31. Goldman H, Cohen D. Periodontal therapy. 6th ed. St. Louis, IL: C.V. Mosby; 1988:921.

32. Basaraba N. Furcation invasions. In: Schluger S, Yuodelis R, Page RC, Johnson RH, editors. Periodontal diseases 2nd ed. Philadelphia: Lea \& Febinger; 1990. 541-559.

33. Gran D, Stern I, Listgarten M. Periodontics, 6th ed. St. Louis, IL: C.V. Mosby; 1988:931.

34. Nevins M, Cappetta EG. Treatment of maxillary furcations. In: Nevins M., Mellonig JT, editors. Periodontal therapy - clinical approaches and evidence of success 1st ed. Chicago: Quintessence; 1998.
35. Ramfjord SP, Ash MM. Periodontology and periodontics, Philadelphia: Saunders; 1979:247-309.

36. Rateitschak KH, Rateitschak EM, Wolf HF. Parodontologie. In: Rateitschak KH, editors. Farbatlanten der zahnmedizin Stuttgart: Georg Thieme Verlag; 1984:50.

37. Carnevale G, Pontoriero R, Lindhe J. Treatment of furcation-involved teeth. In: Lindhe J, Lang NP, Karring T, editors. Clinical periodontology and implant dentistry 2nd ed. Copenhagen: Munksgaard; 1997: 823-847.

38. Walter C, Kaner D, Berndt DC, et al. Three-dimensional imaging as a pre-operative tool in decision making for furcation surgery. J Clin Periodontol 2009;36(3):250-257. DOI: 10.1111/j.1600-051x.2008.01367.x

39. Eskow RN, Kapin SH. Furcation invasions: correlating a classification system with therapeutic considerations. Part I. Examination, diagnosis and classification. Compend Contin Educ Dent 1984;5:527-532.

40. Tarnow D, Fletcher P. Classification of the vertical component of furcation involvement. J Periodontol 1984;55(5):283-284. DOI: 10.1902/jop.1984.55.5.283

41. Tonetti MS, Christiansen AL, Cortellini P. Vertical subclassification predicts survival of molars with class II furcation involvement during supportive periodontal care. J Clin Periodontol 2017;44(11):1140-1144. DOI: 10.1111/jcpe.12789

42. Fedi PF Jr. The periodontal syllabus. 2nd ed. Philadelphia: Lea \& Febinger; 1985:169-170.

43. Ricchetti PA. A furcation classification based on pulp chamber-furcation relationships and vertical radiographic bone loss. Int J Periodontics Restorative Dent 1998;2:50-59.

44. Hou GL, Chen YM, Tsai CC, et al. A new classification of molar furcation involvement based on the root trunk and horizontal and vertical bone loss. Int J Periodontics Restorative Dent 1998;18(3):257-265.

45. Fugazzotto PA. Periodontal-restorative interrelationships: ensuring clinical success. 1st ed. New Jersey: John Wiley \& Sons; 2011:89-115.

46. Rosenberg MM. Management of osseous defects, furcation involvements, and periodontal-pulpal lesions. In: Clinical Dentistry, Periodontal and Oral Surgery, editors. Philadelphia: Harper and Row; 1986.

47. Heins PJ, Canter SR. Furca involvement: a classification of bony deformities. Periodontics 1968;6:84-88.

48. Pilloni A, Rojas MA. Furcation involvement classification: a comprehensive review and a new system proposal. Dent J 2018;6(3):34. DOI: $10.3390 / \mathrm{dj} 6030034$

49. Suh Yl, Lundgren T, Sigurdsson T, et al. Probing bone level measurements for determination of the depths of class II furcation defects. J Periodontol 2002;73(6):637-642. DOI: 10.1902/ jop.2002.73.6.637

50. Smith RG. Gingival recession reappraisal of an enigmatic condition and a new index for monitoring. J Clin Periodontol 1997;24(3):201-205. DOI: 10.1111/j.1600-051x.1997.tb00492.x

51. Ramachandra SS, Mehta DS, Nagarajappa Sandesh M, et al. Periodontal probing systems: a review of available equipment. Periodontics 2009;3(3). 